\title{
Probable Case of Vertical Transmission of SARS-CoV-2 in a Newborn in Mexico
}

\author{
Marcela Mendoza-Hernández ${ }^{a}$ Ivette Huerta-Niño de Rivera ${ }^{a}$ \\ María Yoldi-Negrete ${ }^{b}$ Pamela Saviñon-Tejeda ${ }^{a}$ Rafael Franco-Cendejas ${ }^{c}$ \\ Luis Esaú López-Jácome ${ }^{c}$ Iñaki Navarro-Castellanosd, e
}

aDepartment of Neonatology, Hospital "Dalinde", Mexico City, Mexico; b Department of Research, "Subdirección de Investigaciones Clínicas", National Institute of health Psychiatry "Ramón de la Fuente Muñíz", Mexico City, Mexico; 'Department of Infectious Disease, National Institute of Mental Health Rehabilitation, Mexico City, Mexico; dPediatric Cardiology Department, CHU Sainte-Justine, Université de Montréal, Montreal, QC, Canada; ePediatric Cardiology Department, Hospital "Regional Lic. Adolfo López Mateos", "Instituto de Seguridad y Servicios Sociales", Mexico City, Mexico

\section{Established Facts}

- Some coronaviruses have a vertical route of transmission.

- Vertical transmission has not been confirmed in SARS-CoV-2.

\section{Novel Insights}

- A positive baby was born to a positive asymptomatic mother.

- Vertical transmission was highly likely to have occurred.

\section{Keywords}

Severe acute respiratory syndrome coronavirus $2 \cdot$ Vertical transmission · Epidemiology

\section{Abstract \\ Background: Much remains unknown about the transmis- sion of the SARS-CoV-2 virus. Pregnant women are consid- ered part of the risk population, and vertical transmission of other coronaviruses has been suggested; however, this type of transmission in SARS-CoV-2 is believed to be unlikely. Case Report: A newborn delivered in term via cesarean section to}

an asymptomatic but COVID-19-positive 35-year-old woman started with respiratory distress in the first $30 \mathrm{~min}$ of life. A chest radiograph revealed pneumothorax and ground glass opacities. Ventilatory support with continuous positive airway pressure was needed. Given the respiratory failure and the positive test from the mother, the patient was sampled for SARS-CoV-2 (RT-PCR) at minute 30 of life, with a positive result reported at $36 \mathrm{~h}$ of life. No complications had been present during pregnancy, and cardiac screening and blood cultures revealed no other etiologies. Conclusion: Vertical transmission was highly likely in this case. Clinicians should be alert and report similar cases.

(c) 2021 S. Karger AG, Basel
Correspondence to:

Iñaki Navarro-Castellanos, inaki.navarro@ umontreal.ca 


\section{Introduction}

In the end of 2019, a pneumonia of unknown cause originated in Wuhan, China. A new member of the family of the coronaviruses was discovered and later named SARS-CoV-2. As a new viral agent, all humans are vulnerable [1].

Much remains yet unknown about the transmission of this virus. It is believed that it shares, like others in this family, tropism for rhinopharyngeal secretions [2, 3]. It has also been found in feces, serum, urine, semen, tears, and conjunctival secretions [3-7]. Although pregnant women are considered part of the risk population, and a vertical transmission of other coronaviruses has been suggested [8], this type of transmission in SARS-CoV-2 was believed to be unlikely for several reasons: no cases had been reported; in neonatal cases of COVID-19, presence of SARS-CoV-2 in the placenta has not been reported, and most of the cases with mild respiratory symptoms are considered as adaptation in the context of a transient tachypnea of the newborn [9]; symptoms of reported neonatal cases had appeared at the earliest days after birth even when the mother was positive, and most of the neonatal cases were negative for the test [10].

So far, the possibility of COVID in neonates is apparently uncommon, and the rate of infection seems to remain small when the baby is born vaginally, breastfed, or allowed contact with the mother $[11,12]$. Vertical transmission is of great concern for obstetricians and neonatologists for the risk it imposes on the newborn and is a major public health concern, for a new way of transmission demands different preventive measures.

\section{Case Presentation}

The mother of the patient is a 35 -year-old woman who lives in Mexico City, with no prior medical conditions, in a normal weight range, with no history of smoking. This was her third pregnancy, with two prior cesarean sections. Blood type was $\mathrm{AB}$ negative. Following established institutional protocol for SARS-CoV-2 management, both parents were tested before admission, and both had a positive result for SARS-CoV-2 obtained by real-time reverse transcription polymerase chain reaction (RT-PCR) of a nasopharyngeal sample 2 days prior to delivery. They were both asymptomatic.

The newborn is a male, delivered by cesarean section at 38 weeks of pregnancy, with no complications during pregnancy, weighing 3,110 g, obtaining a 1-min Apgar score of 7 and a 5-min Apgar score of 8 and a Silverman score of 2 , and requiring supplemental oxygen and oropharyngeal suctioning. After the delivery, given the positive test result in the mother, the newborn was not exposed to family members and was transferred to the Neonatal Intensive Care Unit in a solitary sealed room with independent ventilation with the CO-

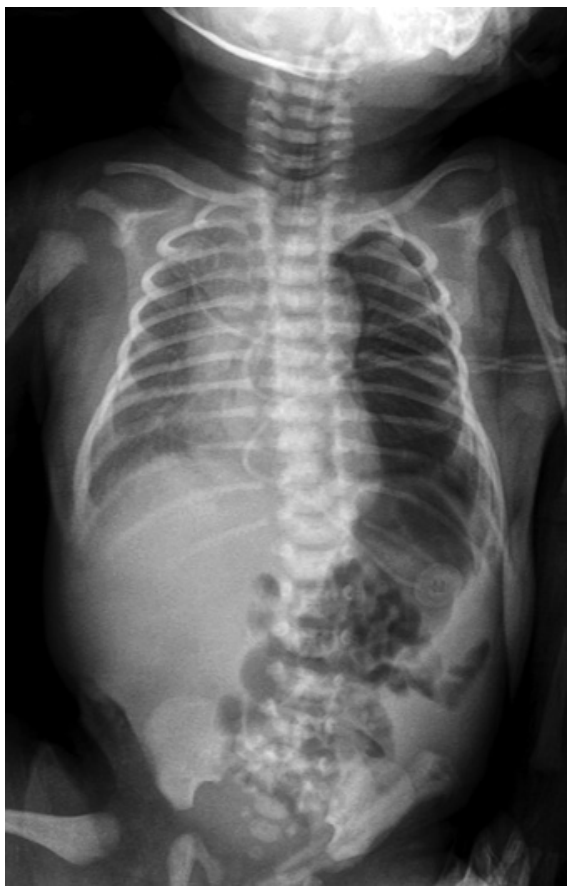

Fig. 1. Chest X-ray showing left pneumothorax.

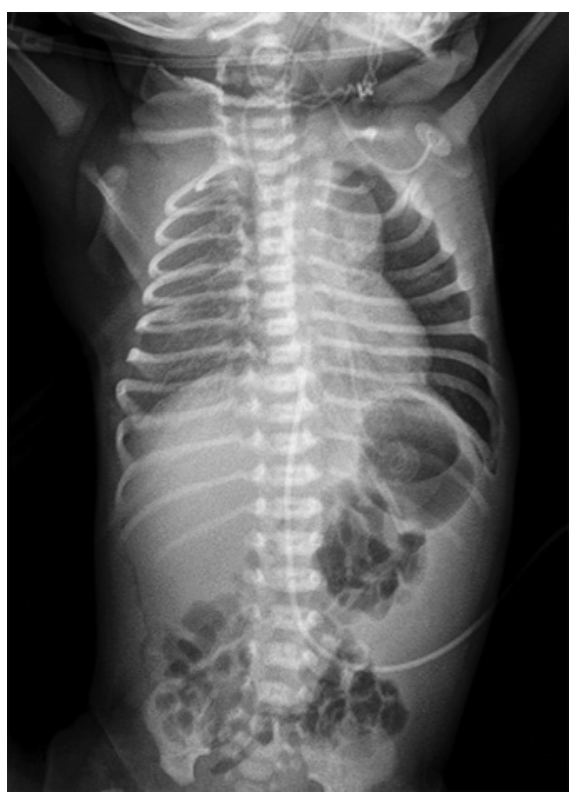

Fig. 2. Second chest X-ray showing resolved pneumothorax and ground glass opacities mainly in the right perihilar region.

VID-isolation technique (all personal protected with KN95 mask, glasses, double globes, and Tyvek ${ }^{\circledR}$ Coveralls). At minute 30 of birth, an RT-PCR test for detection of SARS-CoV-2 in a sample of nose and throat swab was performed. He started with respiratory distress in the first 30 min of life needing supplementary oxygen with an oxygen reservoir reaching supplement oxygen up to $100 \%$; 
as there was no improvement, a chest X-ray was requested, showing left pneumothorax with an extension of over $30 \%$, for which a pleural miniseal was placed reaching lung expansion (Fig. 1). However, ventilatory support with continuous positive airway pressure was still needed. At $12 \mathrm{~h}$ of life, a blood sample was obtained: Hb 14.6 g/dL, WBC 15,140, Neut 79\%, Lymph 13\%, Mono 8\%, C-reactive protein $1.1 \mathrm{mg} / \mathrm{dL}$, and procalcitonin $23.2 \mathrm{ng} / \mathrm{mL}$. A new chest radiograph detected ground glass opacities mainly in the right perihilar region (Fig. 2). Wide spectrum antibiotics were started (ampicillin [50 mg/kg/do q8h] and cefotaxime [50 mg/kg/do q12h]). A transthoracic echocardiogram performed before intubation reported normal cardiac anatomy (normal mitral valve and nonpulmonary vein stenosis), systolic pulmonary pressure $60 \mathrm{~mm} \mathrm{Hg}$ (70 $\mathrm{mm} \mathrm{Hg}$ systolic systemic pressure) measured by aortopulmonary gradient $10 \mathrm{~mm} \mathrm{Hg}$, severe tricuspid insufficiency, moderate pulmonary insufficiency, mild dilatation of right cavities, normal biventricular function, no pleural-pericardial effusion, and coronaries without dilatation. At $20 \mathrm{~h}$ of life, the patient presented with clinical deterioration, and capillary blood gas analysis revealed transient mild acidosis ( $\mathrm{pH}, 7.24$; $\mathrm{pCO}_{2}, 55.4 \mathrm{~mm} \mathrm{Hg} ; \mathrm{pO}_{2} 55$; bicarbonate, $23.4 \mathrm{mEq} / \mathrm{L}$; base excess -4.7 ; and lactate 2.9 ); orotracheal intubation was placed with $\mathrm{FiO}_{2}$ at $100 \%$, and a milrinone 0.3 $\mu \mathrm{g} / \mathrm{kg} / \mathrm{min}$ infusion was started. After intubation, a slight improvement was observed: $\mathrm{pH}=7.33$; $\mathrm{pCO}_{2}=47 \mathrm{~mm} \mathrm{Hg} ; \mathrm{pO}_{2}=51$; bicarbonate $=24 \mathrm{mEq} / \mathrm{L}$; base excess $=-1.7$; and lactate $=2.7$.

At $36 \mathrm{~h}$ of life, the sample for SARS-CoV-2 was reported back as positive. He was reported as stable, still under mechanic ventilation. Blood tests results for inflammatory response were as follows: procalcitonin $38 \mathrm{ng} / \mathrm{mL}(<0.5)$, ALT $14 \mathrm{U} / \mathrm{L}$, AST $79 \mathrm{U} / \mathrm{L}, \mathrm{LD} 933$ U/L (120-246), CK 922 UI/L (46-171), CK-MB 31 ng/mL (0-24), fibrinogen $265 \mathrm{mg} / \mathrm{dL}(200-400)$, and D-dimer $1.5 \mathrm{mg} / \mathrm{dL}(0.05-$ $0.26)$. No other infectious agents were found in cultures. At day 3 , the parents requested to be transferred to a public institution, and further decisions of treatment and diagnosis were out of our hands.

Seven days after delivery, we obtained permission in an institution with the necessary equipment for the analysis of the placenta, fallopian trumps, and cotyledon samples, preserved in formaldehyde, which were extracted by NucliSense EasyMag ${ }^{\circledR}$; Biomerieux, and DNAeasy blood and tissue ${ }^{\circledR}$; Qiagen, and then analyzed as the nose and throat swab with the StepOne Thermocycler (Applied Biosystems) according to Berlin protocol, with negative results for $\mathrm{E}$ and RdRP genes but positive for RNAse $\mathrm{P}$ as internal sample control.

The patient was discharged for recovery from the public hospital at the 4th week, and a follow-up consultation at 3 months old was performed in our outpatient clinic, finding an asymptomatic baby, with normal saturation and respiratory pattern, with no need for supplementary oxygen nor inhaled bronchodilator therapy. There was no evidence of pulmonary sequelae.

\section{Discussion}

Some coronaviruses, such as 229E, OC43, NL63, and HKU1, which are common respiratory viruses, have proven to have a vertical route of transmission [8], and the vertical transmission of SARS-CoV-2 has indeed been suspected by other groups, although with limitations on the evidence necessary to establish causality given negative re- sults of SARS-CoV-2 in the placenta [13-15]. However, there is a recent publication of a patient with fetal distress and positive RT-PCR SARS-CoV-2 in the placenta [16].

The early onset of symptoms (immediately after birth), the lack of comorbidities that could explain the evolution, the early damage in pulmonary tissue as shown in the thoracic $\mathrm{X}$-ray, a positive test in the mother, a positive result (RT-PCR test) for SARS-CoV-2 in the patient, and the inflammatory response with no other infectious agents in cultures make this route of transmission highly probable in this particular case. Even if clinical complications could be explained by other factors, contagion could only have occurred in utero.

Important limitations should be outlined. A confirmatory RT-PCR test was needed. Both the transfer to another institution and a shortage of diagnostic tests in our country, especially at the time this case presented in the pandemic, impeded confirmation. Also, the inadequate management of the placenta, fallopian trumps, and cotyledon increases the possibility that the negative RT-PCR test in these tissues was a false-negative result $[17,18]$.

The purpose of this case report is to alert to the possibility of vertical transmission, even in asymptomatic pregnant women. Suspicion of COVID-19 in newborns with respiratory distress should exist and alert clinicians for precautionary measures both for the newborn and the health personnel. Establishing protocols for adequate preservation and testing of the placenta is an urgent need to confirm or discard beyond doubt this route of transmission.

\section{Conclusion}

We believe that vertical transmission was highly likely to have occurred in this case. Clinicians should be alert and take all the diagnosis and treatment protocols in positive mothers to report similar cases if found.

\section{Acknowledgements}

The authors thank the service of Infectiology of the NIH-Rehabilitation for the processing of RT-PCR of the placenta, fallopian trumps, and cotyledon samples.

\section{Statement of Ethics}

Written informed consent, for the anonymous publication of clinical information and any accompanying images of this case report, was obtained from the parents of the patient. 


\section{Conflict of Interest Statement}

The authors have no conflicts of interest to declare.

\section{Funding Sources}

No funding was received or required.

\section{Author Contributions}

Mendoza-Hernández M.: managed the literature searches, substantial contributions to the conception of the work, revising it critically for important intellectual content, final approval of the version to be published, and agreement to be accountable for all aspects of the work in ensuring that questions related to the accuracy or integrity of any part of the work are appropriately investigated and resolved. Huerta-Niño de Rivera I.: substantial contributions to the conception of the work, revising it critically for important intellectual content, final approval of the version to be published, and agreement to be accountable for all aspects of the work in ensuring that questions related to the accuracy or integrity of any part of the work are appropriately investigated and resolved. Yoldi-Negrete M.: substantial contributions to the design of the work, drafting the work for important intellectual content, final approval of the version to be published, and agreement to be accountable for all aspects of the work in ensuring that questions related to the accuracy or integrity of any part of the work are appropriately investigated and resolved. Saviñon-Tejeda P.: substantial contributions to the conception of the work, revising it critically for important intellectual content, final approval of the version to be published, and agreement to be accountable for all aspects of the work in ensuring that questions related to the accuracy or integrity of any part of the work are appropriately investigated and resolved. Franco-Cendejas R.: managed the literature searches, substantial contributions to the conception of the work, revising it critically for important intellectual content, final approval of the version to be published, and agreement to be accountable for all aspects of the work in ensuring that questions related to the accuracy or integrity of any part of the work are appropriately investigated and resolved. López-Jácome L.E.: substantial contributions to the conception of the work, revising it critically for important intellectual content, final approval of the version to be published, and agreement to be accountable for all aspects of the work in ensuring that questions related to the accuracy or integrity of any part of the work are appropriately investigated and resolved. Navarro-Castellanos I.: managed the literature searches, substantial contributions to the conception and design of the work, drafting the work and revising it critically for important intellectual content, final approval of the version to be published, and agreement to be accountable for all aspects of the work in ensuring that questions related to the accuracy or integrity of any part of the work are appropriately investigated and resolved.

\section{References}

1 Zhu N, Zhang D, Wang W, Li X, PD, Song J, et al. A novel coronavirus from patients with pneumonia in China, 2019. N Engl J Med. 2020;382(8):727-33.

2 Sizun J, Yu MWN, Talbot PJ. Survival of human coronaviruses $229 \mathrm{E}$ and OC43 in suspension and after drying on surfaces : a possible source of hospital-acquired infections. J Hosp Infect. 2000;46:55-60.

3 Ling Y, Xu S-B, Lin Y-X, Tian D, Zhu Z-Q, Dai F-H, et al. Persistence and clearance of viral RNA in 2019 novel coronavirus disease rehabilitation patients. Chin Med J. 2020 May 5;133(9):1039-43.

4 Hindson J. COVID-19: faecal-oral transmission? Nat Rev Gastroenterol Hepatol. 2020; 17:259.

5 Xia J, Tong J, Liu M, Shen Y, Guo D. Evaluation of coronavirus in tears and conjunctival secretions of patients with SARS-CoV-2 infection. J Med Virol. 2020 Jun;192(6):589-94.

6 Kim J-M, Kim HM, Lee EJ, Jo HJ, Yoon Y, Lee $\mathrm{N}-\mathrm{J}$, et al. Detection and isolation of SARSCoV-2 in serum, urine, and stool specimens of COVID-19 patients from the Republic of Korea. Osong Public Health Res Perspect. 2020 Jun 30;11(3):112-7.

7 Massarotti C, Garolla A, Maccarini E, Scaruffi $\mathrm{P}$, Stigliani S, Anserini P, et al. SARS-CoV-2 in the semen: where does it come from? Andrology. 2021 Jan 13;9(1):39-41.
8 Gagneur A, Dirson E, Audebert S, Vallet S. Materno-fetal transmission of human coronaviruses: a prospective pilot study. Eur J Clin Microbiol Infect Dis. 2008;27(2008):863-6.

9 Alonso Díaz C, Lopez Maestro M, Moral Pumarega MT. Primer caso de infección neonatal por SARS-CoV-2 en España. First case of neonatal infection due to SARS-CoV-2. An Pediatr (Barc). 2020 Apr;92(4):237-8.

10 Peng Z, Wang J, Mo Y, Duan W, Xiang G, Yi M. Unlikely SARS-CoV-2 vertical transmission from mother to child: a case report. J Infect Public Health. 2020 Jan; 13:818-20.

11 Coronado Munoz A, Nawaratne U, McMann D, Ellsworth M, Meliones J, Boukas K. Lateonset neonatal sepsis in a patient with Covid-19. N Engl J Med. 2020;382(19):e49.

12 Walker KF, O’Donoghue K, Grace N, Dorling J, Comeau JL, Li W, et al. Maternal transmission of SARS-COV-2 to the neonate, and possible routes for such transmission: a systematic review and critical analysis. BJOG. 2020 Oct;127(11):1324-36.

13 Lavizzari A, Klingenberg C, Profit J, Zupancic JAF, Davis AS, Mosca F, et al. International comparison of guidelines for managing neonates at the early phase of the SARS-CoV-2 pandemic. Pediatr Res. 2021 Mar;89(4):940-51.
14 Alzamora MC, Paredes T, Caceres D, Webb CM, Valdez LM, La Rosa M, et al. Severe COVID-19 during pregnancy and possible vertical transmission. Am J Perinatol. 2020;37(8) 861-5.

15 Zamaniyan M, Ebadi A, Aghajanpoor Mir S, Rahmani Z, Haghshenas M, Azizi S. Preterm delivery in pregnant woman with critical COVID-19 pneumonia and vertical transmission. Prenat Diagn. 2020 Apr 17. Epub ahead of print.

16 Schoenmakers S, Snijder P, Verdijk R, Kuiken T, Kamphuis SSM, Koopman LP, et al. Severe acute respiratory syndrome coronavirus 2 placental infection and inflammation leading to fetal distress and neonatal multi-organ failure in an asymptomatic woman. J Pediatr Infect Dis Soc. 2020 Dec;piaa153..

17 Al-Husaini AM. Role of placenta in the vertical transmission of human immunodeficiency virus. 2009. Available from: www.nature. com/jp.

18 Patel PG, Selvarajah S, Guérard KP, Bartlett JMS, Lapointe J, Berman DM, et al. Reliability and performance of commercial RNA and DNA extraction kits for FFPE tissue cores. PLoS One. 2017;12(6):e0179732. 